\title{
2-HYDROXY-4-METHOXYBENZALDEHYDE, AN ASTOUNDING FOOD FLAVORING METABOLITE: A REVIEW
}

NEELIMA RATHI, KEERTHANA HARWALKAR, JAYASHREE V, ASHWANI SHARMA, NAGASHREE N RAO*

Department of Biotechnology, R V College of Engineering, Bengaluru - 560 059, Karnataka, India. Email: nagashreenrao@rvce.edu.in

Received: 08 May 2017, Revised and Accepted: 16 June 2017

\section{ABSTRACT}

Objective: Rich endowment of traditional knowledge plays a critical role in health care, food security, culture, environment and development. Traditional knowledge is also widely used by the aromatic, flavoring, food and health industries. Plant-based traditional medicine has often been used to identify and fast-track the development of modern food and drugs. Plants synthesize such wide array of secondary metabolites that includes alkaloids, glucosinolates, terpenoids and phenylpropanoids. This study is aimed to review on indigenous and exotic medicinal plants containing an astounding food flavoring metabolite; 2-hydroxy-4-methoxybenzaldehyde (HMB).

Material and Method: The review focuses on the isomer of vanillin, 2-hydroxy-4-methoxybenzaldehyde, also called MBALD, HMB, or 2H4MB, a flavor compound that is generally found in the roots and rhizomes of medicinal plants. This food flavoring phenylpropenoid is one of the least investigated isomers of vanillin. HMB is known to exhibit a wide array of medicinal properties. Though the molecular role of these metabolites remains largely unknown, they are known to play a key role in plant-environment interactions/stress response/defence signaling and application in pharmaceutical and nutraceutical industries.

Discussion and Conclusion: One of the key secondary metabolites is the group of phenylproponoids synthesized either through shikimic acid pathway or the malonate/acetate pathway. Phenylalanine ammonia lyase (PAL) is the enzyme involved in phenylpropanoid pathway catalysing the deamination of phenylalanine to synthesize cinnamic acid that subsequently synthesizes variety of phenylpropanoid products. Inspite of its medicinal importance, the regulatory molecular mechanism underlying the biosynthetic pathway is largely unknown.

Keywords: 2-hydroxy-4-methoxybenzaldehyde, Vanillin, Secondary metabolites, Antioxidants, Phenylpropanoid.

(c) 2017 The Authors. Published by Innovare Academic Sciences Pvt Ltd. This is an open access article under the CC BY license (http://creativecommons. org/licenses/by/4. 0/) DOI: http://dx.doi.org/10.22159/ajpcr.2017.v10i10.19729

\section{INTRODUCTION}

The preservation, protection, and promotion of the traditional knowledge-based innovations and practices of local communities are particularly important for developing countries. This knowledge is vital for the conservation of plants and animals, their genetic diversity, and for managing the local environment. It can make a solid contribution to sustainable development and allow an amicable future for all humans. Traditional knowledge is also widely used by the aromatic, flavoring, food, cosmetic, and health industries. Plant-based traditional medicine has often been used to identify and persuade the development of modern medicines and drugs. Plants produce diverse bioactive compounds or natural products that are synthesized as a product of secondary metabolism. These secondary metabolites based on their biosynthetic origins are classified into three major groups: The terpenoids, alkaloids, and the phenolic compounds. These compounds thwart the manifest visible changes driven by biological and non-biological stress and provide a strong defense to the plant [1]. Many of these secondary metabolites have been used as food flavors and health drinks.

In recent years, due to the growing consumer demand for food products free of synthetic chemical additives, increasing attention has been shunted to explore the naturally-occurring bioactive compounds [2,3]. The plant kingdom, with its remarkable diversity of natural compounds, has merited special interest. Plant essential components have been shown to possess multiple and varied biological activities such as antimicrobial, insecticidal [4], and antioxidant properties [5], and they have received much attention to prevent plant and animal diseases as well as to prevent oxidative damage [6].

Among the bioactive compounds present in plants, the phenylpropanoids symbolize the major pool of secondary metabolites, encompassing of nearly $20 \%$ of total carbon in the terrestrial biosphere, with plants synthesizing approximately 10 gigatonnes $\left(10 \times 10^{9}\right.$ tonnes of carbon $)$ of these molecules each year [7]. Plant phenolics in plants are present as amides, esters, glycosides of hydroxycinnamic acids, flavonoids, and proanthocyanidins and in addition are present as polyphenols such as tannins, anthocyanins, and lignins. One of the well-known phenylpropanoids is vanillin (4-hydroxy-3-methoxybenzaldehyde) that is mainly used as a flavoring agent/additive to foods and beverages and in addition as an intermediate for various pharmaceuticals. Vanillin also serves as an antioxidant, or at least as one of the contributing components, as shown in Saccharomyces boulardii [8]. Vanillin is naturally obtained from vanilla beans, however, the beans are expensive; therefore, the compound is either extracted from lignin waste or from eugenol (a readily available ingredient) or guaiacol. Lignin-based vanillin is said to have a richer flavor profile than oilbased flavoring mainly due to the presence of acetovanillone in the lignin-derived product [9]. Production of vanillin from guaiacol is synthesized through electrophilic aromation substitution on reaction with glycoxylic acid; which results in synthesis of vanillylmandelic acid which is then converted 4-hydroxy-3-methoxyphenylglyoxylic acid and vanillin by oxidative decarboxylation [10]. Other methods of vanillin synthesis are from cow dung [11], 4-hydroxybenzaldehyde [12], 3-bromo-4-hydroxybenzaldehyde [13], tyrosine [14], vanillic acid [15], glucose [16], ferulic acid [17], 0-benzylvanillic acid [18], and 3-methoxy-4-hydroxybenzyl alcohol [19]. The functional properties of vanillin include food additive [20], antioxidant [21], antimicrobial, antifungal [22], antidiabetic, anti-inflammatory, analgesic, and anticancer activities [23]. It has also been found to have antimutagenic effects in mice [24] and bacteria [25].

The review focuses on the isomer of vanillin, 2-hydroxy-4methoxybenzaldehyde, also called MBALD, HMB, or 2H4MB, a flavor 
compound that is generally found in the roots and rhizomes of medicinal plants. It has the chemical formula $\mathrm{C}_{8} \mathrm{H}_{8} \mathrm{O}_{3}$, and its molecular weight is 152.147, same as vanillin; the difference being in the positions of the hydroxyl and methoxy groups.

HMB has so far been found in the essential or volatile oils on extraction from roots with various solvents including dichloromethane, methanol, petroleum ether, and ethyl acetate [26,27]. The presence of HMB in the extract has been confirmed using thin-layer chromatography, the solvent system being hexane:benzene (1:1); this technique, coupled with observation under short length ultraviolet, has facilitated in determining the presence of this hydroxybenzoate [28]. The identification of this compound, however, has been validated using ${ }^{13} \mathrm{C}$ nuclear magnetic resonance (NMR), ${ }^{1} \mathrm{H}$ NMR, infrared spectroscopy, and mass spectroscopy primarily to determine various ionic groups and their arrangements [29,30].

The best method for the extraction of HMB and other volatile oils is reported to be through steam hydrodistillation, proved in case of Decalepis hamiltonii and Hemidesmus indicus roots [31]. HMB is purported to exhibit antibacterial, antifungal, anti-inflammatory, antipyretic, chemoprotective, hepatoprotective, neuroprotective, and antioxidant properties. The most popular plant species that synthesize this bioactive compound are D. hamiltonii, H. indicus, Mondia whitei, Periploca sepium, and Sclerocarya caffra.

\section{D. hamiltoni}

D. hamiltonii Wight and Arn. (Fig. 1a-j) is the sole species of the genus Decalepis. It is endemic to peninsular India, known commonly as swallow root and is known colloquially as Makali beru in Kannada and Magali kizhangu in Tamil. The roots of this plant are used in food flavors, ayurvedic medicines, and in making pickles and health drinks. It belongs to the family Asclepiadaceae [32]. It is also used as a blood purifier, preservative, and as a source of bioinsecticide for storing food grains [33]. Earlier studies have shown that the roots contain aldehyde, inositols, saponins, amyrins, and lupeol [34] as well as volatile compounds such as HMB, vanillin, 2-phenyl ethyl alcohol, benzaldehyde, and others. The active compounds present in Decalepis are $\mathrm{HMB}$, vanillin, and other vanillin-like isomers. Among the volatile oil that can be extracted from the naturally grown root $(0.68 \%)$, HMB was found to be the major component (96\%) [35] produced primarily in roots and in other parts of the plant this metabolite is negligible, which is why the root is favored for making pickles, digestive drinks, as an appetizer, vitalizer, blood purifier, tonic, demulcent, diaphoretic, diuretic, and tonic [36]. It possesses potent antioxidant properties [37], antiulcer [38], anti-inflammatory, antipyretic [39], and gastroprotective activities. In addition, 4-hydroxyisopthalic acid, 14-amino tetradecanoic acid, 4-(1-hydroxy-1-methylethyl)-1-methyl-1,2-cyclohexanediol, 2-(hydroxymethyl)-3-ethoxy benzaldehyde, 2,4,8-trihydroxy bicycle (3.2.1) octan-3-one, bis-2,3,4,6-galloyl- $\alpha / \beta$-D-glucopyranoside, borneol, and ellagic acid have been identified in Decalipes [22,41].

Various studies have been performed to prove that the extract of this root has antioxidant, antibacterial, antifungal, insecticidal, antiulcer, cryoprotective, antipyretic, anxiolytic, chemoprotective, antidiabetic, hepatoprotective, and neuroprotective properties [24]. Antifungal property of $D$. hamiltonii root against seed-borne fungi of paddy was found to be similar to that of a synthetic fungicide but with the added advantage of retaining the nutritional properties [40]. The active ingredient responsible for the root's antifungal activity was reported to be HMB [30]. Although Decalepis is a decisively accredited medicinal plant, majority of available reports in this plant pertains to pharmaceutical/nutraceutical value of this plant, in vitro micropropagation and assessing the antibacterial and insecticidal properties. There are no reports on the elicitation studies in the in vitro cultures of the plant.

\section{H. indicus}

H. indicus Linn. R.Br is a twining shrub, belonging to the family Asclepiadaceae (Fig. $1 \mathrm{k}$ and $\mathrm{l}$ ). The plant is commonly called Anantmul or Indian sarsaparilla. H. indicus is an important medicinal plant known for multipurpose uses since ancient times. The plant is a perennial twiner or creeper, rootstock woody, and fragrant. The roots are known to be very aromatic, emanate a pleasant aroma evocative of a blend

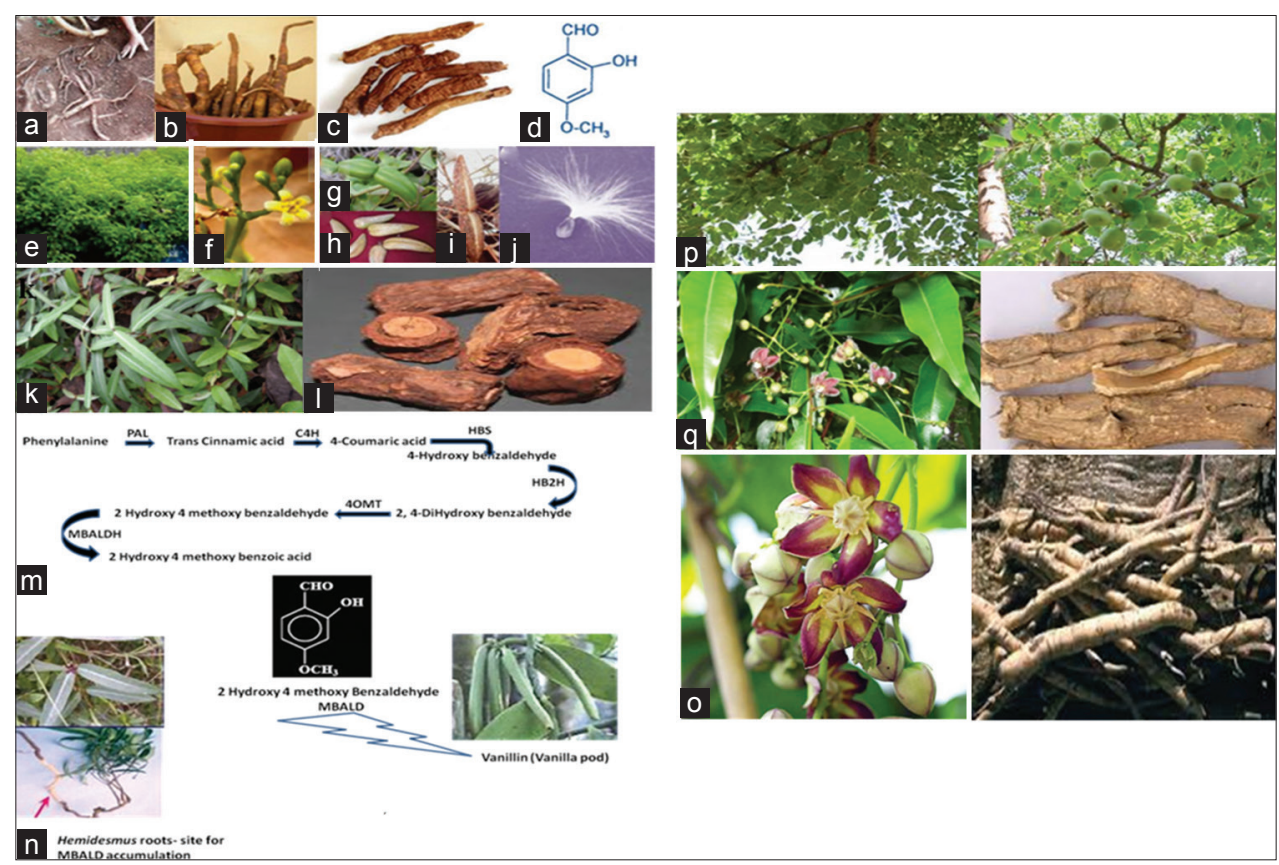

Fig. 1: (a) Circular trench to harvest the roots of Decalipes. (b) Bunch of harvested tuberous roots. (c) Dried tuberous roots of Decalipes. (d) Root-specific flavor metabolite HMB. (e) Canopy of Decalipes. (f) Inflorescence with ovoid, pentameric, actinomorphic flower.

(g) Immature follicle. (h) Dried follicle. (i) Fruit on the state of dehiscence. (j) Obovate flattened seed with coma of white hairs.

(k) Hemidesmus plant. (1) Its root, (m) probable enzymatic route of MBALD in Hemidesmus roots, (n) phenolic fragrance in Hemidesmus indicus root organ, (o) White's Ginger (Mondia whitei) flower, and magical roots, (p) Chinese silk vine (Periploca sepium) (q) flower and roots of Sclerocarya birrea 
of vanilla, cinnamon, and almonds hence its used to make beverages and also used in traditional medicine. It is used in the form of powder, infusion, or decoction as syrup. The syrup made with an infusion of the roots is used to make a Sherbet in the Southern part of India.

Roots of this taxon have been used in folk medicine as well as in ayurvedic and unani preparations. The roots have been prescribed against inflammation, diarrhea, respiratory disorders, skin diseases, syphilis, fever, bronchitis, asthma, eye diseases, epileptic fits in children, kidney and urinary disorders, loss of appetite, burning sensation, and rheumatism [42]. It has also been used in combination with other drugs for snake bite [43]. This plant has been used to treat against viper venom hemotoxic-induced lethality [44] and against hypercholesterolemia in hyperlipidemic rats [45]. However, sufficient scientific standards or parameters are not available to ascertain the identity and to determine the quality of this crude drug. The root paste of this plant has been shown to heal wounds, resulting in lighter and smooth scar formation; the paste also seems promising in the treatment of chronic wounds [46].

A phenolic compound, MBALD and its corresponding benzoic acid derivatives are responsible for the fragrance in root organs. The MBALD structure showed apparent similarity with the structure of vanillin (Fig.1 $\mathrm{m}$ and $\mathrm{n}$ )

The root extracts of $H$. indicus roots and Vanilla planifolia pods rich in MBALD and 4-hydroxy-3-methoxybenzaldehyde (vanillin) have been widely used as flavors for food preparation, in addition, MBALD is known to inhibit the activity of the enzyme acetylcholinesterase, hence these plant-based food flavors can be used for curing neurodegenerative disorders specially the Alzheimer's disease [26].

\section{M. whitei}

M. whitei (Hook. F.) Skeels (Apocynaceae) is also known as mondia or White's ginger (Fig. 10). Mondia is a vigorous climber (3-6 m high) with attractive heart-shaped leaves with vanilla aroma. It is widely distributed in Tropical Africa from Guinea through Cameroon to East Africa. Mondia has been a popular medicine in several African countries and has been continuously used by traditional medicine traders for a long time [47]. The dried roots of Mondia are chewed and the sap is swallowed for appetite stimulation, stomach pain, indigestion and body pain, gastrointestinal disorders, gonorrhea, post-partum bleeding, pediatric asthma, and to stop vomiting [48]. Mondia is used as an aphrodisiac across the globe by many tribes. In Cameroon, the fresh root bark is used to increase libido and in Ghana, to increase sperm production. With the constant administration of $M$. whitei root and bark extract, enhancement of androgenic properties in male rats was exhibited [49-51].

Biochemical studies of Mondia from root extracts have revealed that HMB and an unknown alkaloid exhibit tyrosinase activity [52]. A chlorinated coumarin lignan (5-chlopropacin) has also been found in the roots of $M$. whitei [53]. ${ }^{13} \mathrm{C}$ NMR studies, coupled with ${ }^{1} \mathrm{H}$ NMR, infrared spectroscopy and MS analysis studies have proved the presence of HMB in the root isolates; further organoleptic assays confirmed that this compound was responsible for the bitter-sweet taste as well as the aroma of $M$. whitei roots [32]. Due to the plants medicinal uses, interest has begun to explore the cultivation rather than only the collection of this plant. Little has been reported on the small-scale field cultivation of this plant. Mondia can be easily vegetatively propagated and grows well under a range of soil and environmental conditions. A successful in vitro propagation method has been developed for Mondia [54].

\section{P. sepium}

P. sepium commonly called as Chinese silk vine belongs to the family Asclepiadaceae and is widely distributed in China (Fig. 1p). The root barks of $P$. sepium have been used as a traditional Chinese medicine for the treatment of rheumatoid arthritis and wounds. However, toxicity at high doses was often observed due to the presence of cardiac glycosides. Previous phytochemical studies on P. sepium [55] have reported the presence of pregnane glycosides, cardiac glycosides, oligosaccharides, coumarins, flavonoids, and triterpenoids. The bioactive components present have been reported to possess insecticidal activity [56,57]. An essential oil and HMB present in P. sepium exhibited antimicrobial, antifungal, and antioxidant activities [58].

\section{S. birrea}

S. birrea (A. Rich.) Hochst. subsp. caffra (Sond.) Kokwaro (marula) (Fig. 1q) is a common and widespread fruit-bearing tree species throughout Sub-Saharan Africa [59]. It is frequently a community dominant and hence is a keystone species in plant and animal community ecology and productivity. It is also widely used by rural populations in most countries wherever it grows [60-62]. The fruits are eaten fresh or fermented to make a beer, the kernels are eaten, and the leaves are browsed by livestock. The fruit pulp being used to produce a jelly and to flavor liquor. The in vitro protein digestibility of $S$. birrea was almost similar to that of soybean protein concentrate and lupine. The fruits and the bark are reported to have several medicinal properties [63]. The wood is carved into utilitarian items such as spoons and plates as well as decorative items. S. birrea has been part of a supplemental diet in many countries, and its leaves, fruits, and kernels consumption are becoming increasingly popular with less information on the phytochemicals in this tree. These phytochemicals have been used as nutraceuticals and functional foods. Crude fixed seed oil is a valuable source of essential fatty acids, tocopherols, phytosterols, and phospholipids [64]. HMB, an astounding molecule produced from various plants, has flavoring properties similar to vanillin has been exploited tremendously.

\section{CONCLUSION}

Plant cell and tissue culture hold great promise for controlled production of a myriad of useful secondary metabolites. The utilization of plant cells for the production of natural or recombinant compounds of commercial interest has gained increasing attention over past decades. Food and food additives have been an asset for the human survival from the time immortal, let it be either for the nutrition, cosmetic, or pharmaceuticals. Secondary metabolites from the plant source have always been an enigma for entire biological systems which have been produced from various metabolic pathways.

The phenylpropanoid pathway is one of the key secondary metabolite biosynthetic pathways that synthesize phenolic compounds like the flavonoids, anthocyanins, lignins, coumarins, etc., on being triggered by various stresses. Phenylalanine ammonia lyase (PAL; EC 4.3.1.24) is one of the important enzymes involved in phenylpropanoid pathway catalyzing the first step in phenylpropanoid pathway, it is involved in deamination of Phenylalanine to synthesize cinnamic acid that later branches to synthesize a wide variety of phenylpropanoid products [65]. From the studies made in Arabidopsis thaliana, it is evident that PAL represents the regulatory point between the primary and the secondary metabolite pathway $[66,67]$. The shikimate pathway is one of the major biosynthetic pathways in microorganisms, fungi, and plants that play an essential role in the production of precursors for aromatic amino acids:Phenylalanine, tryptophan, and tyrosine [68-70]. It can be hypothesized that hydroxybenzoates, including $\mathrm{HMB}$, are most likely produced through either of these two pathways or by crosstalk between the two. Studies on H. indicus indicate a sharp increase in the levels of PAL as well as shikimate dehydrogenase on elicitation $[26,71]$, thus helping to conclude that $\mathrm{HMB}$ regulation is linked to these pathways.

In Arabidopsis, PALs are encoded by a multigene family, namely, PAL1, PAL2, PAL3, and PAL4. pal 1 and pal2 mutant generated yellow seeds due to lack of anthocyanin pigment synthesis. PAL1 and PAL2 play redundant roles in flavonoid biosynthesis. On the other hand, the quadruple pal Arabidopsis mutant showed stunted vegetative growth and was sterile. The plants showed enhanced susceptibility to Pseudomonas sp and produced decreased level of salicylic acid, 
suggesting the role of $P A L$ gene in stress-related responses [68]. Overexpression of PAL gene in the transgenic roots of Coleus blumei, a medicinal plant of the lamiaceae family resulted in reduced growth. Amount of total phenolics and the amount of major phenolic compound in the plant are rosmarinic acid whose biosynthesis in C. blumei starts with L-phenylalanine, similar to the pathway in case of HMB biosynthesis. Induction of PAL enzyme generally leads to an increase in phenylpropanoid accumulation in most plants; however, this was not true in case of overexpression of the same in transgenic roots, as reported in C. blumei [67]. The level of the major phenolic compound in a species has a limit, and on overexpression of this compound, it undergoes feedback inhibition to lower the compound levels. Therefore, overexpression studies in the roots/rhizome of HMB-producing plants may not have the desired effect, but regulated expression of $P A L$ gene under tissue-specific promoters might give insights to understand feedback mechanism. MYB transcription factors (TFs) are key regulators of the synthesis of phenylpropanoidderived compounds. NAC domain-containing TFs act as key regulators of secondary cell wall formation [72].

Plant's defence hormone jasmonic acid is known to trigger the biosynthesis of several secondary metabolites through extensive transcriptional reprograming leading to activation of the entire secondary metabolic pathways, and JAs-responsive AP2/ERF, bHLH, MYB, and WRKY TFs are known to be involved in JAs-induced accumulation of secondary metabolites $[1,73]$

Phenylpropanoid compounds impart many properties to food as color (anthocyanins), astringency (phenolic acids), flavor (vanillin), and fibers (lignin). Recently, considerable amount of focus is for the potential benefits ascribed to regular ingestion of the certain phenylpropanoid-derived compounds including lignin, stilbines, and isoflavanoids. Understanding in the area of source of synthesis of various secondary metabolites and its site of action, mode of action, and its regulation is meager. Hence, the genomic and proteomic approach will assist in deciphering the various TFs, signaling molecules, protein transporters, enzymes, and other factors that are involved in secondary metabolite synthesis. Omics studies can be further extended to identify the plants defensive traits and to comprehend the mechanism as to how plants stunt and allocate the resources for the normal primary metabolism and secondary metabolism [71], but the study on the molecular mechanism underlying this regulation is inadequate. Hence, there is a need to intensify the research in identifying the key players and the plant hormones in regulating the secondary metabolite biosynthesis.

The research carried out in HMB suggests that it has a huge biological, food as well as therapeutic potential. However, this compound has been found to be root specific, having negligible levels of HMB in the other parts of the plant, and thus leading to excessive uprooting of such species. This exploitation has led to the endangerment of HMBproducing plants. Unfortunately, unlike vanillin, a synthetic method of producing HMB has not been discovered as of yet. As an alternative, if the biosynthetic pathway of HMB production was known at molecular level, regulated expression of the genes encoding for the relevant enzymes involved in its biosynthesis could aid in increasing the levels. Despite the advances made, there are still many queries to be answered, especially, in context to secondary metabolite production in plants. Furthermore, the more intricate questions related to the secondary metabolite pathways is how the levels of these compounds are sensed, and the feedback mechanism occurs to limit the synthesis of this compound in the plant.

Plants containing HMB have diverse properties in food, medicinal, ayurveda, siddha, and folk system of medicine such as blood purification, wound healing, bronchial asthma, fever, intrinsic hemorrhage, kushtha, erysipelas, poisoning, pediatric rejuvinative, and general vitalizer. Chewing the roots and drinking Nannari (a herbal drink prepared from roots by the Yanadi tribe) from Hemidesmus and Decalipes is considered as good digestive aid and appetizer. Due to the health promoting properties of its roots, pickles and juices are prepared. In various food and pharmaceutical applications, it is used as a preservative due to the bacteriostatic properties of its volatile principle compound. HMB can also find its role in enhancement of the food and food supplements as enriched formulations in the form of beverages, tonics, and confectionaries.

This review is conglomeration of various plants containing HMB and its vast and diversified application which has become a part and parcel of traditional knowledge of medicine as well as modern drug and in food industries. Although a lot of research has been carried out, still the mode and mechanism of this metabolite are a mystery. Plants with HMB have great potential to be industrialized into resource food and other health products. There lies a huge gap between laboratories to land technologies which are to be addressed to safeguard the valued traditional knowledge. Due to overexploitation and habitat destruction, plants with HMB have become endangered and vulnerable in its natural habitat. Hence, there is an urgent need to conserve these red listed endangered plants.

\section{ACKNOWLEDGMENT}

Authors would like to thank the Department of Biotechnology (DBT) for financial support. Authors extend their concede to RSST and R V College of Engineering for all the support and encouragement.

\section{REFERENCES}

1. Zhou M, Memelink J. Jasmonate-responsive transcription factors regulating plant secondary metabolism. Biotechnol Adv 2016;34(4):441-9.

2. Burt S. Essential oils: Their antibacterial properties and potential applications in foods-a review. Int $\mathrm{J}$ Food Microbiol 2004;94(3):223-53.

3. Bakkali F, Averbeck S, Averbeck D, Idaomar M. Biological effects of essential oils-a review. Food Chem Toxicol 2008;46(2):446-75.

4. Dudareva N, Negre F, Nagegowda DA, Orlova I. Plant volatiles: Recent advances and future perspectives. Crit Rev Plant Sci 2006;25:417-40.

5. Umesh TG. In vitro callus induction and antioxidant potential of Decalepis hamiltonii (Wight and Arn). Int J Pharm Pharm Sci 2014;6(6):452-6.

6. Tripathi P, Dubey NK. Exploitation of natural products as an alternative strategy to control Syzygium jambos against selected human pathogens. Int J Pharm Pharm Sci 2011;3(2):44-7.

7. Yu O, Jez JM. Nature's assembly line: Biosynthesis of simple phenylpropanoids and polyketides. Plant J 2008;54(4):750-62.

8. Suryavanshi A, Agarwal A, Kaler A, Bihade U, Kaur J, Kulbhushan B, et al. Comparative studies on the antioxidant potential of vanillinproducing Saccharomyces boulardii extracts. Oxid Antioxid Med Sci 2013;2(3):201-9.

9. Brenes M, García A, García P, Rios JJ, Garrido A. Phenolic compounds in Spanish olive oils. J Agric Food Chem 1999;47(9):3535-40.

10. Mackie DM, Smith D, Aitkin RA. Guidebook to Organic Synthesis. Vol. 12. New York, USA: Longman; 1990.p. 103-19.

11. Yamamoto M. Yamamoto and Dung Vanilla, Japan Probe Aroma Research. Vol. 7; 2006. p. 258-80.

12. Douglass F, Patel S, Travis M, Winkel EE. Vanillin synthesis from 4-hydroxybenzaldehyde. J Chem Educ 2007;84(7):1158-62.

13. Tahir A. Synthesis of Vanillin, Valhalla. J Chem Educ 1999;12:24-46.

14. Gary M, Andrews J, Bratz W, Hanssen O, Perry D. Preparation of vanillin from eugenol and sawdust. J Chem Educ 1977;54(12):776-8.

15. Gross GG. Formation and reduction of intermediate acyladenylate by aryl-aldehyde. NADP oxidoreductase from Neurospora crassa. Eur J Biochem 1972;31(3):585-92.

16. Snell K. Synthesis modification of the Escherichia coli chromosome: Enhancing the biocatalyst conversion of glucose in to aromatic chemicals. J Am Chem Soc 1996;118(24):5605-14.

17. Falconnier B. Vanillin as a product of ferulic acid biotransformation by the white-rot fungus Pycnoporuscina barinus: Identification of metabolic pathway. J Bio Technol 1994;37:123-32.

18. Li T, Rosazza JP. Biocatalytic synthesis of vanillin. Appl Environ Microb 2000;66(2):684-7. 
19. Ming H, Shi Y. La-containing sba- $15 / \mathrm{h} 2 \mathrm{o} 2$ systems for the microwave assisted oxidation of a lignin model phenolic monomer. Madras Cienc Y Tecnol 2010;12(3):181-8.

20. Burri J, Graf M, Lambelet P, Löliger J. Vanillin: More than a flavoring agent-a potent antioxidant. J Sci Food Agric 1989;48(1):49-56.

21. Kamat JP, Ghosh A, Devasagayam TP. Vanillin as an antioxidant in rat liver mitochondria: Inhibition of protein oxidation and lipid peroxidation induced by photosensitization. Mol Cell Biochem 2000;209(1-2):47-53.

22. Boonchird C, Flegel TW. In vitro antifungal activity of eugenol and vanillin against Candida albicans and Cryptococcus neoformans. Can J Microbiol 1982;28(11):1235-41.

23. Kumar R, Sharma PK, Mishra PS. A review on the vanillin derivatives showing various biological activities. Int $\mathrm{J}$ Pharm Tech Res 2012;4(1):1251-61.

24. Imanishi H, Sasaki YF, Matsumoto K, Watanabe M, Ohta T, Shirasu Y, et al. Suppression of 6-TG-resistant mutations in V79 cells and recessive spot formations in mice by vanillin. Mutat Res 1990;243(2):151-8.

25. Ohta T, Watanabe M, Shirasu Y, Inoue T. Post-replication repair and recombination in uvrA umuC strains of Escherichia coli are enhanced by vanillin, an antimutagenic compound. Mutat Res 1988;201(11):107-12

26. Kundu A, Jawali N, Mitra A. Shikimate pathway modulates the elicitorstimulated accumulation of fragrant 2-hydroxy-4-methoxybenzaldehyde in Hemidesmus indicus roots. Plant Physiol Biochem 2012;56:104-8.

27. Chandrasekhara MR, Murthy KS. A review on Decalepis hamiltonii Wight and Arn. J Med Plants Res 2013;7(41):3014-29.

28. Chidambara KN, Rajashekaran T, Giridhar P, Ravishankar GA. Antioxidant property of Decalepis hamiltonii Wright and Arn. Indian J Exp Bio 2006;44:832-7.

29. Mukonyi KW, Isaiah ON. 2-hydroxy-4-methoxybenzaldehyde: Aromatic taste modifying compound from Mondia whitei. Bull Chem Soc Ethiop 2001;15(2):137-41.

30. Mohana DC, Raveesha KA, Lokanath KM. Herbal remedies for the management of seed-borne fungal pathogens by an edible plant Decalepis hamiltonii (Wight and Arn). Arch Phytopathol Plant Prot 2008;41(1):38-49.

31. Nagarajan S, Rao LJ. Determination of 2-hydroxy-4-methoxy benzaldehyde in roots of Decalepis hamiltonii (Wight and Arn.) and Hemidesmus indicus R. Br. J AOAC Int 2003;86(3):564-7.

32. Prajapati DS, Purohit SS, Sharma AK, Kumar T. Handbook of Medicinal Plants: Complete Source Book. Vol. 6. Jodhpur: Agrobios; 2001. p. 548-62.

33. George J, Pereira J, Divakar S, Udaysankar K, Ravishankar GA. A Method for the Preparation of Active Fraction from the Root of Decalepis hamiltonii, Useful as Bioinsectiside. Indian Patent No. 1301/98; 1998

34. Murti PB, Sheshadiri TR. A study of the chemical compounds of Decalepis hamiltonii. Proc Indian Acad Sci 1941;14:93-9.

35. Nagarajan S, Rao LJ, Gurudutt KN. Chemical composition of the volatile of Decalepis hamiltonii (Wright and Arn). Flavor Fragrance J 2001;16:27-9.

36. Vedavathy S. Decalepis hamiltonii Wight and Arn.-an endangered source of indigenous health drink. Nat Prod Radiance 2004;3:22-3.

37. Srivastava A, Harish RS, Shivanandappa T. Antioxidant activity of the roots of Decalepis hamiltonii (Wright and Arn). LWT Food Sci Tech 2013;39:1059-65.

38. Lin J, Opoku AR, Geheeb-Keller M, Hutchings AD, Terblanche SE, Jäger AK, et al. Preliminary screening of some traditional zulu medicinal plants for anti-inflammatory and anti-microbial activities. J Ethnopharmacol 1999;68(1-3):267-74.

39. Parekh J, Chanda S. In vitro antimicrobial activities of extract of Launaea procumbens Roxb. (Labiateae), Vitis vinifera (Vitaceae) and Cyperus rotundus (Cyperaceae). Afr J Biomed Res 2006;9:89-93.

40. Murugan S, Devi PU, Parameswari NK, Mani KR. Antimicrobial activity of postharvest fungal rotting of fruit and vegetables. Postharvest Biol Technol 2004;32:235-45.

41. Laxmi A, Siddhartha S, Archana M. Antimicrobial screening of methanol and aqueous extracts Swertia chirata. Int J Pharm Pharm Sci 2011;3(4):142-6

42. Shahzad A, Sharma S, Siddiqui SA. Biotechnological Strategies for the Conservation of Medicinal and Ornamental Climbers. Vol. 2. Switzerland: Springer International Publishing; 2016. p. 169-84

43. Nadkarni AN. Indian Material Medica. $1^{\text {st }}$ ed., Vol. 1. Bombay, India: Popular Book Depot; 1989. p. 619.
44. Alam MI, Audpy B, Gomes A. Viper venom neutralization by Indian medicinal plants (Hemidesmus indicus and Pluchea indica). Phytother Reson 1996;10:58-61.

45. Bopanna KN, Bhagyalakshmi N, Rathod SP, Balaraman R, Kannan J. Cell culture derived Hemidesmus indicus in the prevention of hypercholesterolemia in normal and hyperlipidemic rats. Indian $\mathrm{J}$ Pharmacol 1997;29:105-9.

46. Kumari KV, Nishteswar K. Phytochemical and clinical evaluation of Sariba (Hemidesmus indicus) on wound healing. Int Res J Pharm 2012;3(3):277-81

47. Kokwaro JO. Medicinal Plants of East Africa. Nairobi: Kenya Literature Bureau; 1976.

48. Neuwinger HD. African traditional medicine. A Dictionary of Plant Use and Applications. Germany: Medpharm Scientific Publ.; 2000. p. 5

49. Watcho P, Donfack MM, Zelefack F, Nguelefack TB, Wansi S, Ngoula F, et al. Effects of the hexane extract of Mondia whitei on the reproductive organs of male rat. Afr J Tradit Complement Altern Med 2005;2(3):302-11.

50. Watcho P, Kamtchouing P, Sokeng S, Moundipa PF, Tantchou J, Essame JL, et al. Reversible antispermatogenic and antifertility activities of Mondia whitei L. in male albino rat. Phytother Res 2001;15(1):26-9.

51. Watcho P, Kamtchouing P, Sokeng SD, Moundipa PF, Tantchou J, Essame JL, et al. Androgenic effect of Mondia whitei roots in male rats. Asian J Androl 2004;6(3):269-72.

52. Nihei K, Yamagiwa Y, Kamikawa T, Kubo I. 2-hydroxy-4isopropylbenzaldehyde, a potent partial tyrosinase inhibitor. Bioorg Med Chem Lett 2004;14(3):681-3.

53. Patnam R, Kadali SS, Koumaglo KH, Roy R. A chlorinated coumarinolignan from the African medicinal plant, Mondia whitei. Phytochemistry 2005;66(6):683-6.

54. Afolayan AJ, Adebola PO. In vitro propagation: A biotechnological tool capable of solving the problem of medicinal plants decimation in South Africa. Afr J Biotech 2004;3:683-7.

55. Wei Y, Zhao L, Deng Y. Research advance on the chemical components of Periploca sepium and the pharmacological action. J Tianjin Univ Tradit Chin Med 2009;28:165-6.

56. Miyazawa M, Fujita T, Yamafuji C, Matsui M, Kasahara N, Takagi Y, et al. Chemical composition of volatile oil from the roots of Periploca sepium. J Oleo Sci 2004;53:511-3.

57. Shi Q, Ma Y, Qin H. Chemical components and insecticidal activity of essential oil in Periploca sepium root bark to Schizaphis graminum. Acta Bot Boreal Occident Sin 2006;26:620-3

58. Wang J, Liu H, Zhao J, Gao H, Zhou L, Liu Z, et al. Antimicrobial and antioxidant activities of the root bark essential oil of Periploca sepium and its main component 2-hydroxy-4-methoxybenzaldehyde. Molecules 2010;15(8):5807-17.

59. Peters CR. Notes on the distribution and relative abundance of Sclerocarya birrea Hochst. (Anacardiaceae). Mono Syst Bot Mo Botan Gardens 1988;25:403-10.

60. Shackleton CM. Growth and fruit production of Sclerocarya birrea in the South African lowveld. Agrofore Syst 2002;55:175-80.

61. Shackleton CM, Dzerefos CM, Shackleton SE, Mathabela FR. The use and trade in indigenous edible fruits in the Bushbuckridge savanna region, South Africa. Ecol Food Nutr 2000;39:225-45.

62. Shackleton CM, Shackleton SE. Direct use values of savanna resources harvested from communal savannas in the Bushbuckridge lowveld, South Africa. J Trop Forest Prod 2000;6:21-40.

63. Mariod A, Abdelwahad S. Sclerocarya birrea (Marula), An African tree of nutritional and medicinal uses: A review. Food Rev Int 2012;28:375-88

64. Aganga AA, Mosase KW. Tannin content, nutritive value and dry matter digestibility of Lonchocarpus capassa, Zizyphus mucronata, Sclerocarya birrea, Kirkia acuminate and Rhus lancea seeds. Anim Feed Sci Tech 2001;91(1-2):107-13.

65. Chakraborty D, Sircar D, Mitra A. Phenylalanine ammonia-lyasemediated biosynthesis of 2-hydroxy-4-methoxybenzaldehyde in roots of Hemidesmus indicus. J Plant Physiol 2008;165(10):1033-40.

66. Christopher M, Fraser CC. The Phenylpropanoid Pathway in Arabidopsis. The Arabidopsis Book; 2011. p. 9. DOI: 10.1199/ tab.0152.

67. Huang J, Gu M, Lai Z, Fan B, Shi K, Zhou YH, et al. Functional analysis of the Arabidopsis PAL gene family in plant growth, development, and response to environmental stress. Plant Physiol 2010;153(4):1526-38.

68. Herrmann KM, Weaver LM. The shikimate pathway. Annu Rev Plant 
Physiol Plant Mol Biol 1999:50:473-503

69. Knaggs AR. The biosynthesis of shikimate metabolites. Nat Prod Rep 2003;20(1):119-36.

70. Tzin V, Galili G. The biosynthetic pathways for shikimate and aromatic amino acids in Arabidopsis thaliana. Arabidopsis Book 2010;8:e132.

71. Liu J, Osbourn A, Ma P. MYB transcription factors as regulators of phenylpropanoid metabolism in plants. Mol Plant 2015;8(5):689-708.
72. Zhang L, Chen J, Li Q, Chen W. Transcriptome-wide analysis of basic helix-loop-helix transcription factors in Isatis indigotica and their methyl jasmonate responsive expression profiling. Gene 2016;576:150-9.

73. Dong J, Wan G, Liang Z. Accumulation of salicylic acid-induced phenolic compounds and raised activities of secondary metabolic and antioxidative enzymes in Salvia miltiorrhiza cell culture. J Biotechnol 2010;148(2-3):99-104. 